\title{
Community collaboration and climate change research in the Canadian Arctic
}

\author{
Tristan D. Pearce, ${ }^{1}$ James D. Ford, ${ }^{2}$ Gita J. Laidler, ${ }^{3}$ Barry Smit, ${ }^{4}$ Frank Duerden, ${ }^{5}$ Mishak Allarut, ${ }^{6}$ \\ Mark Andrachuk, ${ }^{7}$ Steven Baryluk, ${ }^{8}$ Andrew Dialla, ${ }^{9}$ Pootoogoo Elee, ${ }^{10}$ Annie Goose, ${ }^{11}$ Theo Ikummaq, ${ }^{12}$ \\ Eric Joamie, ${ }^{13}$ Fred Kataoyak, ${ }^{14}$ Eric Loring, ${ }^{15}$ Stephanie Meakin, ${ }^{16}$ Scott Nickels, ${ }^{17}$ Kip Shappa, ${ }^{18}$ \\ Jamal Shirley ${ }^{19}$ \& Johanna Wandel ${ }^{20}$ \\ 1 Department of Geography, University of Guelph, 50 Stone Road East, Guelph, Ontario N1G 2W1, Canada \\ 2 Department of Geography, McGill University, 805 Sherbrooke St. W., Montreal, Quebec H3A 2K6, Canada \\ 3 Department of Geography and Environmental Studies, Carleton University, 1125 Colonel By Drive, Ottawa, Ontario K1S 5B6, Canada \\ 4 Department of Geography, University of Guelph, 50 Stone Road East, Guelph, Ontario N1G 2W1, Canada \\ 5 Department of Geography, Ryerson University, 350 Victoria Street, Toronto, Ontario M5B 2K3, Canada \\ 6 Hamlet of Arctic Bay, Nunavut XOA OAO, Canada \\ 7 Department of Geography, University of Guelph, 50 Stone Road East, Guelph, Ontario N1G 2W1, Canada \\ 8 Inuvialuit Game Council, P.O. Box 2120, Inuvik, Northwest Territories XOE OTO, Canada \\ 9 P.O. Box 259, Pangnirtung, Nunavut XOA ORO, Canada \\ 10 P.O. Box 142, Cape Dorset, Nunavut XOA OCO, Canada \\ 11 Ulukhaktok, Northwest Territories XOE OSO, Canada \\ 12 P.O. Box 53, Igloolik, Nunavut XOA OLO, Canada \\ 13 P.O. Box 127, Pangnirtung, Nunavut XOA ORO, Canada \\ 14 P.O. Box 34, Ulukhaktok, Northwest Territories XOE 0SO, Canada \\ 15 Inuit Tapiriit Kanatami, 170 Laurier Ave, Suite 510, Ottawa, Ontario K1P 5V5, Canada \\ 16 Inuit Circumpolar Conference, 170 Laurier Ave. West, Suite 504, Ottawa, Ontario K1P 5V5, Canada \\ 17 Inuit Tapiriit Kanatami, 170 Laurier Ave., Suite 510, Ottawa, Ontario K1P 5V5, Canada \\ 18 Hamlet of Arctic Bay, Nunavut XOA OAO, Canada \\ 19 Nunavut Research Institute, P.O. Box 1720, Iqaluit, Nunavut XOA OHO, Canada \\ 20 Department of Geography and Environmental Management, University of Waterloo, 200 University Ave. West, Waterloo, Ontario N2L 3G1, Canada
}

\section{Keywords}

Adaptation; Canadian Arctic; climate change; community-researcher collaboration; Inuit; vulnerability.

\section{Correspondence}

T.D. Pearce, Department of Geography, University of Guelph, 50 Stone Road East, Guelph, Ontario N1G 2W1, Canada.

E-mail: tpearce@uoguelph.ca

doi:10.1111/j.1751-8369.2008.00094.x

\begin{abstract}
Research on climate change impacts, vulnerability and adaptation, particularly projects aiming to contribute to practical adaptation initiatives, requires active involvement and collaboration with community members and local, regional and national organizations that use this research for policy-making. Arctic communities are already experiencing and adapting to environmental and socio-cultural changes, and researchers have a practical and ethical responsibility to engage with communities that are the focus of the research. This paper draws on the experiences of researchers working with communities across the Canadian Arctic, together with the expertise of Inuit organizations, Northern research institutes and community partners, to outline key considerations for effectively engaging Arctic communities in collaborative research. These considerations include: initiating early and ongoing communication with communities, and regional and national contacts; involving communities in research design and development; facilitating opportunities for local employment; and disseminating research findings. Examples of each consideration are drawn from climate change research conducted with communities in the Canadian Arctic.
\end{abstract}

An increasing number of research projects have identified climate change impacts and adaptations in the Canadian Arctic (e.g., Berkes \& Jolly 2002; Fox 2002; Symon et al. 2005; Nickels et al. 2006; Wesche \& Armitage 2006; Ford et al. 2008; Furgal \& Prowse 2008). The experience of climate change in Arctic communities, and their ability to adapt, varies among regions and communities, and within communities, on account of differing geographies, 
histories and social, political and economic contexts (Duerden 2004; Adger et al. 2005). Assessing the vulnerability and adaptive capacity of communities requires research in particular places, recognizing local social and cultural conditions, the broader economic and political environments, and involving the knowledge and experiences of local people (Turner et al. 2003; McCarthy \& Martello 2005; Smit \& Wandel 2006). Such research necessarily entails working with people in communities.

This paper explores challenges in involving Arctic communities in research on climate and other environmental changes, and outlines opportunities for the effective engagement of local people in community-environment research. In this paper, the term, "communityenvironment research" is used to refer to research on climate, and other environmental changes, and their human implications that actively involves the knowledge and experiences of local people. The aim of the paper is to draw from the experiences of projects in the Canadian Arctic, particularly from three case studies, to identify key considerations for effectively engaging Arctic communities in community-environment research.

The paper begins with a short summary of the issue of climate change in the Arctic, followed by a review of the rationale for community involvement in research. A summary of the main types of community-environment research in the Arctic provides an indication of some of the challenges in such research, and outlines the strategies adopted to facilitate community engagement. Four key considerations for effective community engagement are outlined, relating to communication, research design, employment and dissemination of findings. These are illustrated in turn with reference to three case studies, and insights from other community-environment research projects. The case studies, conducted in Nunavut and the Northwest Territories (NWT) between 2002 and 2006, examined relationships between aspects of climate change and people, and involved members of the community.

\section{The Canadian Arctic, climate change and communities}

The Canadian Arctic is defined in this paper as the three territorial administrative regions of the Yukon, NWT and Nunavut, plus the Inuit settlement regions of Nunavik and Nunatsiavut (Fig. 1). Together these regions cover nearly $60 \%$ of the Canadian land mass, encompassing an area that is rich in geographic and biological diversity. Approximately half of the population living in the Canadian Arctic is indigenous, and belongs to distinct cultural and political groups (Furgal \& Seguin 2006).
People living in the Canadian Arctic have experienced rapid social, economic and political changes in the last half of the 20th century, including: settlement in communities; compulsory education; introduction of new technologies; signing of land claim agreements; development of new political institutions and co-management arrangements (e.g., wildlife management); and increasing natural resource extraction and development. In recent years, Arctic communities have also been exposed to hazards associated with climate change. Local observations and instrumental measurements have recorded an increase in the frequency and magnitude of hazardous conditions in the Arctic, including permafrost thaw, coastal erosion, ice instability, and increases in average temperatures and precipitation (Nickels 2006; Furgal \& Prowse 2008). These changes have increased the risks associated with travelling on sea ice, affected access to hunting and fishing areas, and have damaged community infrastructure, for example, buildings, roadways, trails, airports and cultural sites (Instanes et al. 2005; Furgal \& Seguin 2006; Tremblay et al. 2006). Changes have also been documented in the health of wildlife species important for subsistence hunting (Nuttall et al. 2005; Nickels et al. 2006). These changes are expected to continue into the future, with further implications for the Arctic environment and Arctic communities (Symon et al. 2005; Furgal \& Prowse 2008).

In many instances, social change and climate change have acted synergistically to affect Arctic livelihoods and the resources on which they depend. As a result of the interdependence between Arctic communities and global markets, Arctic communities are exposed to changes in market processes, technologies and public policies, and to outside political and economic situations. Whereas in the past people often relocated or changed resource use activities in response to environmental changes, today people do not have such flexibility because they live in permanent communities, and are involved in wage employment and resource management arrangements (e.g., quota systems) (McCarthy \& Martello 2005). Current and future climate change impacts have created a growing urgency amongst communities, governments, and regional and national indigenous organizations to improve our collective understanding of how Arctic communities will be affected by climate change, and how they might deal with or adapt to these changes (GeoNorth 2000; GN 2003; Shirley 2005; Watt-Cloutier et al. 2005; Handley et al. 2007).

Given this interest in the effects of climate change on Arctic environments and communities, several, sometimes complementary, research foci have been adopted, including: global climate modelling (McCarthy et al. 


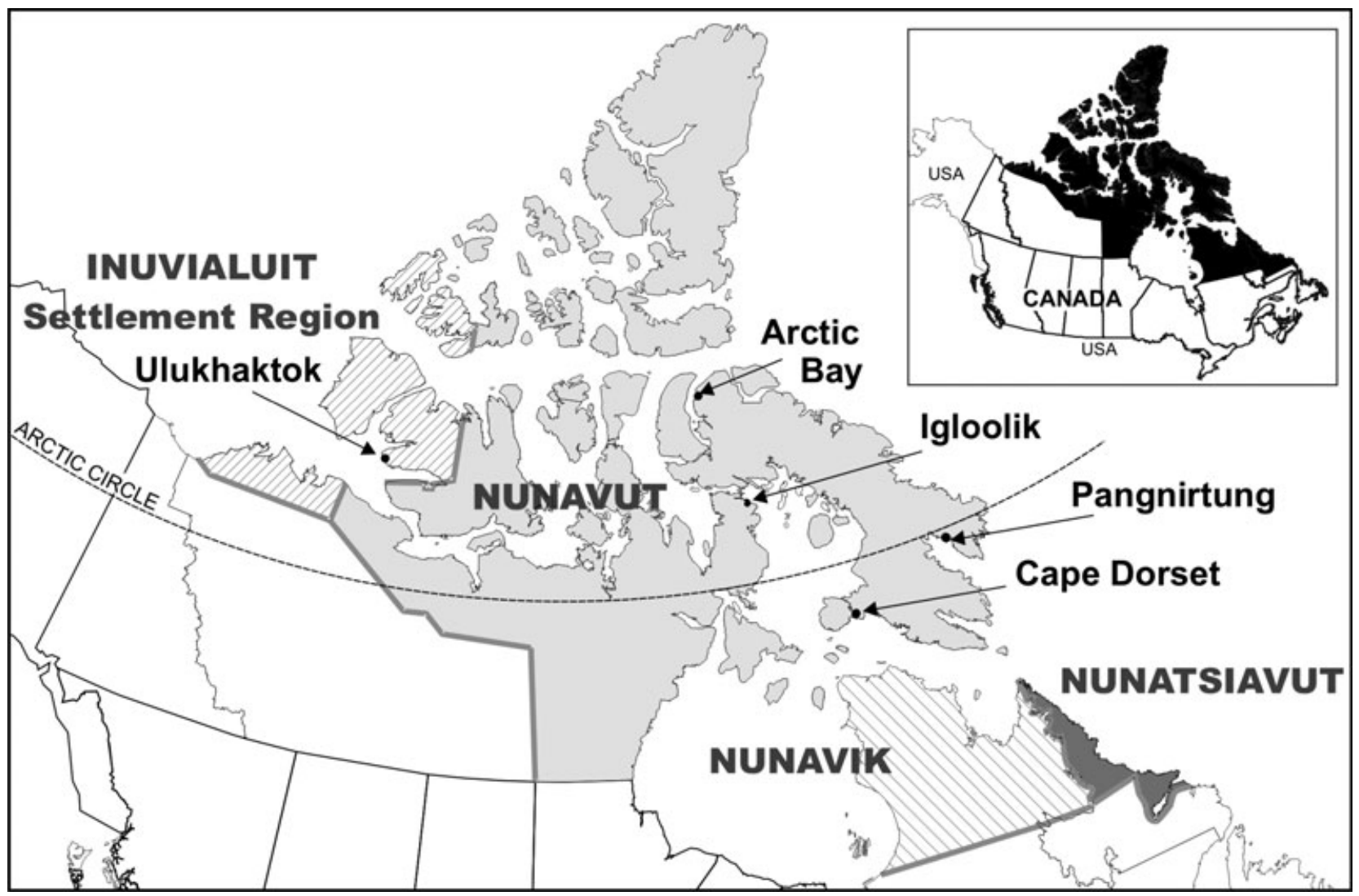

Fig. 1 Location of the case-study communities: Ulukhaktok, Arctic Bay, Igloolik, Cape Dorset and Pangnirtung.

2001; Symon et al. 2005); recording indigenous observations of environmental change (Fox 2002; Nichols et al. 2004; Nickels et al. 2006); analyses of community sustainability (Kruse et al. 2004; Crate 2006); studies of social-ecological resilience (Berkes \& Jolly 2002; Chapin et al. 2006); and assessment of community vulnerability (Tyler et al. 2007; Ford et al. 2008). Common findings from these bodies of work are that changes are occurring that have significant implications for Arctic peoples, and that there is a need for an enhanced understanding of the human dimensions of environmental change. It is also apparent that community-environment research necessitates input from local people, and several projects have actively involved community members in the research process.

\section{Why involve communities in community-environment research?}

The rationale for, and importance of, community engagement are summarized here according to practical, ethical and regulatory considerations.

\section{Practical considerations}

Community collaboration in community-environment research is important because effective research cannot be done without community involvement; it is difficult, if not impossible, to identify who is vulnerable to what stresses, and in which way and why, without community collaboration. Furthermore, adaptations to climate change are not isolated from other decisions, but occur in the context of local demographic, cultural and socioeconomic conditions. Adaptations are more likely to be successful and meaningful to individuals and communities if they are identified and developed in collaboration with communities (Sallenave 1994; Chapin et al. 2006; Ford et al. 2007; Wolfe et al. 2007). The knowledge and information that Arctic peoples hold and the importance of local involvement in policy-driven research is reflected in the inclusion of traditional knowledge in environmental assessment (Stevenson 1996; Usher 2000), climate change assessment (GN 2003; GY 2006; GNT 2008), and land and resource management across Canada's Arctic regions (Duerden \& Kuhn 1998; Berkes et al. 2001; Ellis 2005). Research approaches that are inconsistent with 
Northern expectations or community involvement can result in faulty data collection, misinterpretation, community dissatisfaction, and, in some cases, the prohibition of research by communities (Gearheard \& Shirley 2007).

\section{Ethical considerations}

Researchers have an ethical obligation to engage with the people who are the focus of the research. As Northerners are the individuals experiencing the conditions being researched, and also live with the impact of the research, researchers have a responsibility to involve community members. However, researchers and community members do not necessarily have the same views about appropriate research objectives and methods. What may be perceived as culturally acceptable in an academic or professional culture may not be considered acceptable according to the culture of the local community (Gibbs 2001; Wiita 2006). Researchers can work with local people on developing the research foci, objectives and methods to ensure that the research is being undertaken in a locally acceptable fashion. Several publications outline ethical principles for the conduct of research involving people in northern Canada (e.g., ACUNS 2003; CIHR 2007; ITK \& NRI 2007). These principles relate to respecting local laws, protocols, cultural norms, language, traditions, knowledge, confidentiality, acknowledgement and consent, and ensuring the privacy and dignity of people (ACUNS 2003). Just as researchers clearly benefit from the knowledge collected in the research process, many communities in northern Canada also regard scientific research as a useful tool to help provide the information needed to publicize issues of importance to them, so as to raise awareness and inform policy initiatives (ITK \& NRI 2007). They often seek partnerships in the research process to serve these purposes: to influence the chosen foci of research, to maintain a degree of ownership, and to provide employment and skills development opportunities for community members.

\section{Research regulations}

With the signing of land claim agreements across the Canadian Arctic, indigenous peoples have gained significant control over decisions affecting their environment and communities, including the type and nature of research conducted in their communities and regions. Northern research institutes require researchers to engage communities in the design and development of research as a part of the protocol for research licensing. For example, under the Nunavut Land Claim Agreement of 1993, all research in Nunavut is licensed by the Nunavut Research Institute (NRI). Among other requirements for applications, researchers are strongly encouraged to engage Nunavut community authorities and other local and regional agencies that may be affected by, and/or have an interest in, the proposed research, to discuss their research plans, and to incorporate feedback and suggestions (NTI 2008). Elsewhere in Canada, funding agencies, government departments, universities and Northern research institutes increasingly recognize the importance of involving communities in research, and have developed requirements and licensing procedures and protocols for conducting research with Northern communities (CYFN 2000; ACUNS 2003; ARCUS 2004; ARI 2004; CIHR 2007; Eamer 2006; NCP 2007).

\section{Community-environment research in the Arctic}

Researchers continue to develop and refine methods for involving Northern people and their knowledge in research (Sallenave 1994; Cohen 1997; Huntington 2000; Nickels et al. 2002; Brooks et al. 2006; Gearheard \& Shirley 2007; Wolfe et al. 2007). Despite an increasingly common claim by researchers that their projects engage local people and knowledge, few studies in the Arctic report the methods they use to engage with communities. This section outlines some ways that Northern people have been engaged in community-environment research, and identifies key issues and challenges in facilitating this engagement. With the proliferation of research on climate change impacts, vulnerability, resilience and adaptation in the Arctic, different interpretations of community engagement are evident. For some, community engagement may involve hiring a local assistant or attending a community meeting, whereas for others it may involve community collaboration in research design and development, inclusion of traditional knowledge or participatory action research. Ultimately, each research project will necessitate or incite different levels of community interest and involvement based on the topic and goals (ITK \& NRI 2007), and will therefore have different experiences and various degrees of success in engaging communities (Gearheard \& Shirley 2007).

A common situation in which communities are engaged in research is through measuring changes in the Arctic environment (e.g., measuring sea-ice characteristics, seal monitoring). In this context, community engagement often takes the form of hiring and training local people as field researchers. It may also include involving local people as informants, interpreters, guides and research partners. Communities have also been invited to share traditional knowledge of Arctic humanenvironment systems, and the complex social and environmental factors that underpin them. The term 
"traditional knowledge" is used here, consistent with its use by Huntington (1998), Berkes (1999), Noongwook et al. (2007) and the Government of the NWT to mean "knowledge and values, which have been acquired through experience, observation, from the land or from spiritual teachings, and handed down from one generation to another" (GNT 2005). The term "traditional ecological knowledge" (TEK) has been used by various commentators, either as a synonym for traditional knowledge or referring to those aspects of traditional knowledge that relate to ecosystems and human interactions with the environment (Wenzel 1999). The term traditional knowledge is sometimes interchanged with "aboriginal knowledge" or "indigenous knowledge" when pertaining to specific cultural groups (Stevenson 1996; Usher 2000; GNT 2005), and sometimes "local knowledge" is used to refer to information from community members regardless of culture or inter-generational history.

Researchers working in northern Canada, particularly on projects that document traditional knowledge, have a long history of engaging Arctic communities. Boas' (1888) work on the relationship between sea-ice types, ringed seal abundance and Inuit settlement patterns represents an early example of systematic research carried out among Canadian Inuit (Wenzel 1999). Traditional knowledge and community involvement are explicit in the ethnographies produced by Stefansson (1913), Jenness (1922), Rasmussen (1932) and Birket-Smith (1929). Arctic communities have been engaged to share their knowledge in land-use studies (Freeman 1976; Brice-Bennett 1977; Riewe 1992), harvest studies (IJS 2003; Gamble 1984) and research on subsistence (e.g., Kemp 1971; Freeman 1976; Keene 1985; Smith and Wright 1989; Noongwook et al. 2007). Cultural anthropologists, archaeologists and other social scientists have involved Arctic communities in their research (e.g., Damas 1963; Wenzel 1981; Bielawski 1984; Condon et al. 1995; Collings et al. 1998; Tester 2006), and several researchers working in the sub-Arctic regions of Canada (e.g., Cree and Athabascan societies) have also engaged with communities (e.g., Nelson 1969, 1973; Feit 1973; Brody 1981; Fienup-Riordan 1983; Ohmagari \& Berkes 1997).

In the more recent work on community-environment issues, numerous researchers have engaged communities to document traditional knowledge related to changing environmental conditions. These studies have used participatory research methods, including community workshops (Nickels et al. 2006), semi-directed interviews and focus groups (Huntington 1998; Noongwook et al. 2007), mapping (Tremblay et al. 2006; Laidler \& Elee 2008), stakeholder meetings (Woo et al. 2007) and guided trips on the land/sea ice (Berkes et al. 2000;
Gearheard et al. 2006). In some studies, community engagement is limited to meetings in which scientific information is shared, and feedback is sought from local representatives. In other studies, community engagement involves the collection of traditional knowledge with minimal local involvement in other aspects of the research, such as topic selection, interpretation and application. Traditional knowledge is treated as one source of data contributing to Western scientific research. If communities are the intended end-users of the research, such studies may have limited relevance to local concerns or interests (Kruse et al. 2004). To address this challenge, researchers are increasingly involving communities throughout the research process, including research design and application, and interpretation and verification of results (Berkes \& Jolly 2002; Nickels et al. 2006). In doing so, researchers are attempting to incorporate both traditional knowledge and Western scientific knowledge to help direct the research process, and inform decision making.

However, the integration of scientific knowledge and traditional knowledge in research is difficult in practice (Freeman 1992; Usher 2000; Noongwook et al. 2007; Wolfe et al. 2007). The process of community engagement has proven to be complex, and researchers and communities face challenges when forging communityresearch relationships. Key challenges include: local employment trends and attitudes, revolving membership and leadership of community organizations, concurrent local activities at the time of research, cultural differences, poor historical research community-researcher relations, economic subtext of many community-research relationships, financial limitations, time constraints and communicating results to stakeholders (Wiita 2006; ITK \& NRI 2007; Gearheard \& Shirley 2007; Wolfe et al. 2007). Some of these challenges are inevitable given the contexts in which community-research relationships are often developed (e.g., government and university funding structures, timing constraints in academic programs, resource development pressures and new political arrangements). However, efforts are continually being made to reflect upon, and improve, the ways in which community-researcher relations are established and maintained.

Several frameworks and methodologies for participatory research and community-research collaboration have been applied in the Arctic. Wolfe et al. (2007) developed a conceptual framework for interdisciplinary community-environment research that is participatory, iterative and promotes ongoing communication between researchers and community members. The framework was applied in Fort Resolution and the Slave River Delta, NWT, to understand how ecosystems and human com- 
munities respond to environmental change. Researchers were flexible with the timing, duration and nature of research activities, and data collection in the community was adjusted to accommodate local activities and respond to community feedback. The methods used by Berkes $\delta$ Jolly (2002) and Nickels et al. (2006) drew on a series of techniques based on the Ziel Orientierte Projekt Planung (Objectives Oriented Planning; ZOPP) or Global Oriented Project Planning (GOPP) approach, and approaches such as Participatory Rural Appraisal (PRA), to document Inuit traditional knowledge of environmental change (see GTZ 1988; Chambers 1994). GOPP was used to structure and manage community workshops, in which community members identified priority issues and established research questions and methodologies with researchers. In Berkes \& Jolly (2002), researchers made multiple trips to the study community, and focused on data collection and reporting results back to the community. A variety of complementary participatory methodologies were used, including workshops, focus groups, video interviews, semi-directive interviews and participant-observation.

Several documents exist to help guide researchers and Northerners through the process of undertaking studies in Canada's northern regions. Eamer (2006) summarizes procedures for research licensing in northern Canada (including NWT, Yukon, Nunavut and the northern provinces), and ITK \& NRI (2007) provide advice to assist researchers working with Inuit communities in the Inuvialuit Settlement Region, Nunavut, Nunavik (northern Quebec) and Nunatsiavut (Labrador). Gearheard \& Shirley (2007) discuss sources of community-research conflict in physical science research in Nunavut and opportunities to avoid such conflicts. Messages in these documents are generally consistent with this paper, which focuses upon community collaboration (not licensing) for research that directly involves Northerners and their communities, and that is intended to have both scientific and community relevance.

\section{Case studies illustrating considerations for community engagement}

This paper draws on the experiences of academic and community researchers, as well as representatives of Northern and Inuit organizations who have been involved in community-environment research in the Arctic. Organizations include Inuit Tapiriit Kanatami (ITK), Inuvialuit Joint Secretariat (IJS), Inuit Circumpolar Council (ICC), Nunavut Research Institute (NRI) and Aurora Research Institute (ARI). Key considerations for effectively engaging Arctic peoples in communityenvironment research are identified, and illustrations of each consideration are drawn from case studies of community-environment research in the Canadian Arctic. The three case studies are from: (1) Ulukhaktok, NWT; (2) Arctic Bay and Igloolik, Nunavut; and (3) Cape Dorset, Pangnirtung and Igloolik, Nunavut (Fig. 1). Although the case studies are specific to the Canadian Arctic, the broad elements of performing community research are likely to be applicable in other Northern regions, and for other topics involving communities and/or their lands and resources.

\section{The Ulukhaktok case study}

A study was conducted with the community of Ulukhaktok (formally Holman), a coastal Inuvialuit community of approximately 420 people located on the west coast of Victoria Island in the Inuvialuit Settlement Region of the NWT (GNTBS 2007). The study aimed to identify and describe the ways in which the community is vulnerable to changing environmental conditions. This involved documenting exposure sensitivities and associated adaptive responses employed in the community to deal with variations and changes in physical and socio-economic forces (see Pearce 2006). Data were collected in the community over a four-month period between May and September 2005 through 62 semi-structured interviews with community members, participant observation and an analysis of secondary sources of information (e.g., existing research, wildlife harvest data and economic reports). Research findings were disseminated and feedback provided in the community during an additional two-month visit between mid-July and mid-September 2006.

\section{The Arctic Bay-Igloolik case study}

The Arctic Bay-Igloolik case study refers to collaborations with the Nunavut communities of Arctic Bay and Igloolik over the period 2002-06. Arctic Bay is a coastal community of approximately 700 people located in a mountainous region of north Baffin Island, and Igloolik is a community of 1500 people located on a small island in northern Foxe Basin (Statistics Canada 2006). Researchers worked with Inuit in the communities to identify and characterize vulnerabilities to climate change, and to identify entry points for policies to increase the community adaptive capacity or resilience. A total of 112 semistructured interviews and six focus group sessions were conducted for the project, which were followed up with discussion sessions to review the project results (see Ford, Macdonald et al. 2006; Ford, Smit et al. 2006; Ford et al. 2007; Ford et al. 2008). 


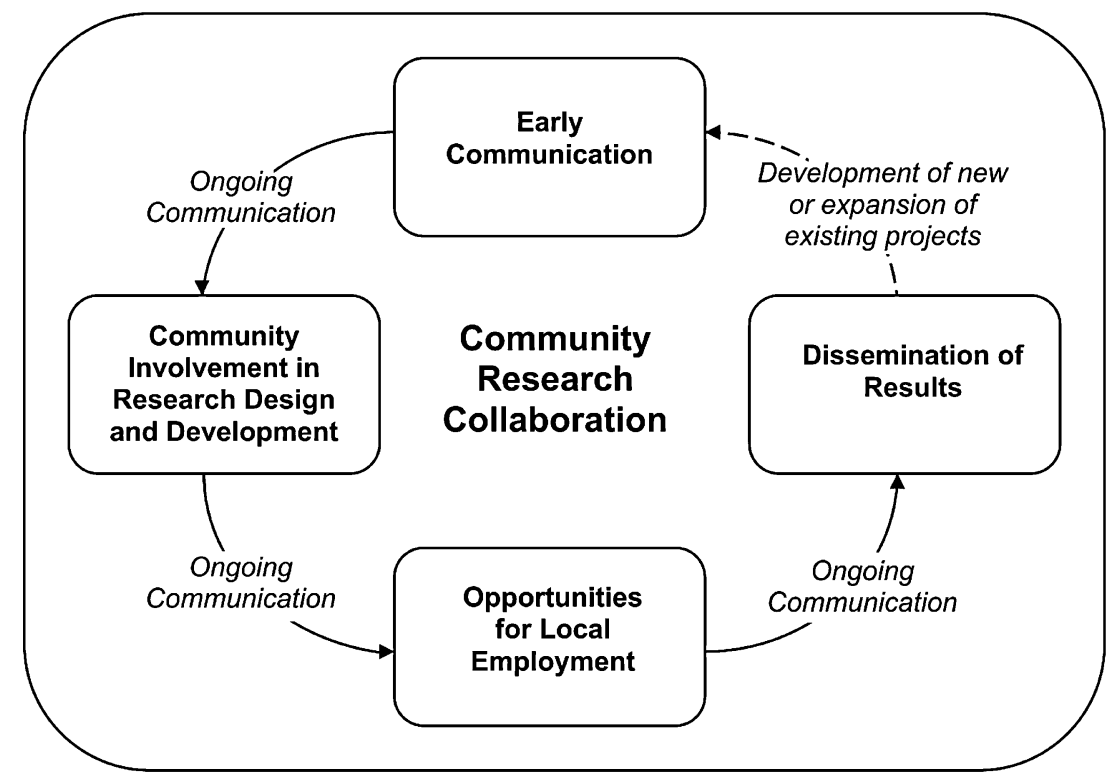

Fig. 2 Key considerations for engaging Arctic communities in collaborative research.

\section{The Dorset-Pang-Igloolik case study}

This study was undertaken with three coastal Inuit communities around Baffin Island, Nunavut: Cape Dorset, Pangnirtung and Igloolik. Cape Dorset, with a population of 1236, is located on a small island of the same name on the south-western tip of Baffin Island (Statistics Canada 2006). Pangnirtung, with a population of 1325, is located on the south-eastern shore of Pangnirtung Fjord on Cumberland Peninsula, off the northern shore of Cumberland Sound (Statistics Canada 2006). This research project aimed to characterize the importance of sea-ice processes, use and change in the three communities, based on Inuit knowledge of local and regional sea-ice conditions. These results can form baseline contributions to more comprehensive vulnerability assessments, as well as provide recommendations for linking Inuit and scientific sea-ice knowledge in a complementary manner. In total, 84 semi-structured interviews with community members (including participatory mapping), 14 experiential sea-ice trips and four focus groups were conducted over several trips to each community, totalling nearly nine months spent in the communities; see Laidler 8 Elee 2008; Laidler \& Ikummaq 2008; Laidler et al. 2008).

These communities are all predominantly Inuit, and have economies based on wage employment and subsistence harvesting. The researchers involved in these case studies sought to work collaboratively with local people, went through the licensing and approval processes, and established local research partnerships. In all three studies the main information sources were the community members themselves, supplemented with data from records, documents and existing research reports. In each case study, researchers, representatives of Northern organizations and community members faced challenges in building collaboration. Lessons from these experiences are drawn on to illustrate considerations for engaging communities in community-environment research in the Canadian Arctic. As illustrated in Fig. 2, these issues are interrelated, but here they are addressed under four categories: (1) initiating early and ongoing communication with community, regional and national contacts; (2) involving communities in research design and development; (3) facilitating opportunities for local employment; and (4) disseminating research findings.

\section{Early and ongoing communication}

Effective early and ongoing communication is essential in developing strong community-research relationships. Effective communication provides opportunities to identify interested community partners, link with existing research projects, develop community-researcher relationships, and communicate research progress and findings in the community. The Canadian Arctic has an extensive network of indigenous organizations and Northern research institutions that are prepared to (and have a mandate to) assist researchers in communicating their project ideas to communities. Early communication can be initiated via any of several routes (e.g., direct contact with communities through established contacts), but many problems can be avoided by going through Arctic indigenous organizations and Northern research institutions, in order to establish research legitimacy by following accepted protocols for contacting and engaging communities. 
In the Dorset-Pang-Igloolik case study, the university researcher was interested in understanding and documenting long-term, detailed, experiential Inuit knowledge of the dynamic sea-ice environment to provide a more comprehensive assessment of the implications of sea-ice change. But, before pursuing this research, confirmation was sought regarding whether this might be of interest to prospective community partners. After conducting extensive literature reviews on the topic of sea ice from both Inuit and scientific perspectives, as well as discussing the project idea with ITK, NRI, Nunavut Tunngavik Inc. (NTI) and Qikiqtani Inuit Association representatives, gaps in this area of research were identified. Inuit and Northern associations also confirmed that the issue was of great importance to nearly all Nunavut communities. Therefore, three collaborating communities (Cape Dorset, Pangnirtung and Igloolik) were selected to be approached with the research idea, in consultation with the aforementioned organizations, as well as through efforts to collaborate with another researcher proposing to work in these locations.

In the Ulukhaktok study, early communication with national and regional Inuit organizations was crucial for identifying local research partners. Early in the planning, researchers contacted ITK for assistance in communicating research ideas to prospective case-study communities. Following recommendations from ITK, researchers provided representatives of the IJS, Inuvialuit Game Council (IGC) and ARI with a written summary broadly outlining the proposed research. These initial communications led to an invitation from the IGC to present the research ideas at an IGC meeting-an opportunity to meet with representatives from each of the six Inuvialuit communities. At this meeting, representatives from Ulukhaktok expressed interest in having the research conducted in their community, citing changes in the environment and community concern for impacts on subsistence activities. Researchers did not select a community a priori, but identified, with community representatives, a case study that suited both the research needs and those of the community.

It is not uncommon for multiple research projects to be underway simultaneously (or recently completed) in a community or a region. In some cases, research projects may be complementary, offering the possibility for collaboration and sharing among researchers. Initiating early communication with community and regional stakeholders provides an opportunity to identify and link with existing research projects or build on earlier studies. Identifying the research that has been conducted and the projects that are underway offers researchers the chance to advance what has been completed, explore certain themes in detail and avoid common concerns expressed by communities that researchers are unaware of other projects and are "always asking the same questions".

In the Arctic Bay-Igloolik study, Arctic Bay was selected because the community was the focus of the Unikkaaqatigiit study being conducted by ITK to document local observations of climate change (Nickels et al. 2006). Recognizing the complementary features of the two studies, researchers used the Unikkaaqatigiit focus groups to introduce their project to community members, obtain feedback and identify key themes and concerns of the community. By linking with the existing study, researchers avoided repeating the focus group exercise, were able to focus the research on concerns already identified by the community (and consistent with the aims of the project), and gained community interest and support in the research. Of course, a balance needs to be found here, as most researchers have only a limited range regarding research topics.

Community-research collaboration has been described as a relationship-building exercise, based on mutual trust and respect (Wiita 2006). Formal and informal communications between researchers and community members play important roles in developing this relationship. In the Ulukhaktok case study, the researcher spent time participating in daily community activities during research visits to the community: visiting public buildings such as the hotel restaurant, Co-op and Northern stores, school, and hamlet office, and developed rapport with many community members. Similarly in the Arctic BayIgloolik and Dorset-Pang-Igloolik studies, the researchers gained familiarity in the communities by billeting with local households during research visits, and participating in community activities such as sports and traditional games. By expressing an interest in and a willingness to learn about local culture and customs, the researchers were welcomed into people's homes for tea and conversation, to join community members on daily excursions on the land and community events, including hunting trips, drum dances, sporting activities and feasts. It was these informal, often subtle, communications between researchers and community members that helped develop the mutual trust and understanding needed for effective community research. It is difficult to systematically evaluate these aspects of communication, but, as is well known by cultural anthropologists and other social scientists (Gearheard et al. 2006; Huntington et al. 2006), informal communications are undoubtedly critical to the success of collaborative endeavours, as they underlie the way that community members perceive a researcher, and thus influence how they wish to work with someone.

A key element in effective ongoing communication in the case studies was the involvement of local researchers-people from the study community who 
were employed as members on the research teams. These people identified appropriate means of communicating with community residents, and often facilitated the information sharing. In the Arctic Bay-Igloolik study, radio, information pamphlets and posters were jointly established by the researchers, research assistants and interpreters to be appropriate mediums for communicating research updates. Radio was especially useful as it is a primary mode of daily communication in the communities. Project updates were broadcasted on the community radio stations to keep community members informed of the projects as they evolved, encourage participation in the research and solicit community feedback (people called in to make comments and suggestions). Information pamphlets and posters were distributed to individuals and organizations to summarize the goals of the project (in the early stages), and to summarize project results (in the later stages). These short, ongoing updates were appreciated by communities, and were effective at keeping communities informed on the progress of the research.

Communication with community members, organizations and local researchers was sometimes difficult to maintain when the academic researchers were not in the settlement: local collaborators might not have easy access to a telephone, fax or the internet; miscommunication can occur over the phone because of language barriers; there are difficulties in discussing the content of publications and other written documents as a result of the limitations of telephone and/or e-mail communication; there is a high turnover rate in local organizations; and/or community members may not be available because of cultural events, hunting activities, etc. However, through the persistent use of multiple mediums of communication, community members and organizations in all of the studies were routinely updated on postfieldwork activities, progress and preliminary results. In addition, opportunities were identified for local researchers to attend and present findings at conferences, pursue follow-up research activities independently and co-author publications.

\section{Community involvement in research design and development}

Involving communities in research design and development is necessary in respect of the community in which the research is to be undertaken, and to learn from the knowledge and experiences of community members in designing feasible, practical and comprehensive research programmes. However, it may require a resolution of differences that may already exist between what the researchers aim to investigate and issues that community members want to have addressed. In the case studies, preliminary consultation visits by researchers were important steps in this process. These meetings helped to develop research foci and methodologies, choose appropriate times of year to conduct fieldwork, and develop positive working relationships between communities and researchers.

In the Ulukhaktok case the importance of researcher flexibility in conducting a preliminary community consultation was particularly important for negotiating the design and timing of the research. Early in the process, the researcher accepted an invitation from the Ulukhaktok Hunters and Trappers Committee (HTC) to visit the community to discuss the proposed research. Depending on the nature of the proposed research, researchers may also choose to initiate early contact with, for example, the Hamlet Council, Community Corporation, health centre, cultural resource centre, school administration, elders and/or youth councils. During the two-week visit, the researcher held several formal and informal meetings with community representatives to discuss the research and gain familiarity in the community. The visit was planned to coincide with regularly scheduled meetings of the HTC, Community Corporation and Hamlet Council. As is commonly the case, meeting dates changed and the researcher had to extend the stay to accommodate the schedules of local participants.

This experience serves as a lesson for the planning of consultations and other visits. Communities comment that researchers too often fly into a settlement for a short duration of time (e.g., one day) and expect to meet with community representatives at that timewhat some communities call "storm trooper" consultation. This does not provide enough time for adequate discussion of a research project, nor does it give enough time for community members to give feedback on the research. Visits from researchers are but one of many activities occurring in Arctic communities at any given time, and researchers wanting to engage communities in research sometimes need to be flexible and accommodating with their time.

During the consultation visit in Ulukhaktok, the researcher established partnerships with local collaborators, addressed language barriers by working with collaborators and interpreters, and began learning about the local culture and community dynamics. Community members and organizations made several recommendations for the research design and development, and confirmed methods already proposed by the researcher, including: conducting field research during sea-ice freeze-up and/or break-up, when community members are not as busy travelling and harvesting; conducting data collection with a local Inuinnaqtun interpreter; training 
and employing local high-school graduates; sharing research results in the community regularly and translating documents into Inuinnaqtun; and disseminating research findings at the local school. Ongoing feedback from local collaborators helped to integrate these recommendations into the research design, building trust in the community, increasing participation in the research and ensuring that information was being collected using locally appropriate methods.

Many research design issues required making compromises. For example, in the Ulukhaktok community, representatives suggested fieldwork take place in the spring and fall during sea-ice freeze-up and/or break-up, when community members would be spending more time in the settlement. However, these times of year did not necessarily match the periods available to the researcher who had to work around academic requirements and constraints. As a compromise, fieldwork was conducted between May and September. Although the summer was not an optimal time to conduct research (many community members were out "on the land"), the researcher adapted by dividing time between conducting interviews with elders (who did not travel) and community members who are employed in the community, and participating in experiential trips on the land. These trips helped the researcher contextualize the information people shared in interviews related to the environment, environmental change and subsistence.

In the Arctic Bay-Igloolik case, linking with an existing research project in Arctic Bay helped frame the research foci, and provided researchers with an opportunity to identify the most appropriate time to conduct the research in the community. Researchers attended community focus groups conducted by ITK, in which many of the climate risks identified by community members concerned the late spring floe-edge narwhal hunt. The hunt is conducted during late spring when the ice is in the final stages of melting prior to break-up. Ice leads, cracks and pools of water on the ice make travel time-consuming and dangerous. Hunters are also at risk of being caught on drifting ice, which is detached from the floe-edge by a southerly wind. After discussions with community members, it was decided to focus the vulnerability assessment on conditions related to subsistence hunting, and the central field research was timed to occur during the narwhal hunt in July. Also, during initial meetings with community members, a preliminary list of local hunters and sea-ice experts was developed, both for information sources and to assist with field research planning.

Preliminary research visits were critical to the initiation of the Dorset-Pang-Igloolik study. Conducted in the fall of 2003 and the winter of 2004, the researcher spent one to one and a half weeks in each study community, meeting with the hamlet councils, hunters' and trappers' associations, elders groups, Qikiqtani Inuit Association representatives, local high schools, Nunavut Arctic College coordinators, visitor's centres and research centres (where possible-not all the communities have the same number of local organizations). These visits included formal and informal meetings with community members to establish research foci that were of local interest and a research design that was appropriate. Existing reports of changing ice had mostly relied on scientific measurements, often limited in attributes considered and local/regional coverage. Community organizations were interested in having local Inuit expert's knowledge of ice recognized in reports and programmes, so this became a central component of the research, and the foundational support from which to plan future visits and objectives.

Also during the Dorset-Pang-Igloolik consultation meetings, community members and organizations emphasized that results must be frequently communicated and made accessible to a community audience. To address these concerns, interim trip reports were developed after each field visit, to provide preliminary results as well as to elicit feedback throughout the project, instead of the community having to wait four years for the "final" results. Furthermore, these consultations helped refine research foci and interview questions, develop a list of local sea-ice experts to interview during subsequent research trips, and decide on the times of year to return for field research (during all stages of sea-ice formation and decay). These interactions helped establish positive working relationships with the communities from the outset. Community members were engaged in the development and design of the research project, and research methods were updated and refined based on local feedback.

Preliminary consultation visits are an opportunity to facilitate local involvement in research design and development. However, the duration and nature of community consultations may be limited by funding and/or time constraints. Travel in the Arctic can be expensive and time consuming, which can be limiting factors for even the best-intentioned researcher. It is therefore important for researchers to factor a preliminary consultation visit into their research plans and budget. Funding agencies are calling for greater community engagement in research, and now often provide funding for consultation visits. In all the case studies, consultation visits to potential partner communities provided opportunities to identify research foci, agree on research methodologies and for the community to get to know the researchers. The consultation visits also allowed the researchers to become more familiar with the social and environmental contexts in which the research was to be conducted. 


\section{Opportunities for local employment}

Most Arctic research projects attempting to understand the connections between livelihoods and environmental change are feasible only with the collaboration of local partners and assistants. These partnerships are also important for the communities, both for providing employment and for providing opportunities for developing research skills. Local employment is important for building community support for and participation in the research, facilitating communication between researchers and communities, and interpreting and verifying data.

By employing local people, researchers in each study gained greater support for the research and received the participation of some community members who otherwise would not have been as willing to participate. For example, in the Arctic Bay-Igloolik study, local researchers were hired based on their knowledge and involvement in hunting, a focus of the research. These researchers were able to identify a list of potential interviewees and local experts, and through their relationships in the community were able to solicit the participation of several key informants. Local researchers guided the research in the community and they taught researchers about local customs, language, and how to best conduct interviews and focus groups. At the same time, local researchers report learning research skills including interviewing, information recording, report writing, and summarizing and presenting findings. Some local researchers report that their experience working on the research project has helped them obtain employment on other research projects, and has given them confidence to initiate their own research activities and to pursue additional skills training (e.g., land-based skills, college, vocational training courses).

In all case studies, interpreters were employed as part of the research team. Interpreters played vital roles in the case study research, including translator, research assistant, community liaison, guide and teacher. Not only did they interpret language, they also interpreted concepts that vary greatly between cultures, societies and languages. Interpreters also helped facilitate interpersonal linkages between the researcher and community members, and collaborated in the refinement of research questions and methods to more adequately reflect locally accepted practices. Their language and interpersonal skills were essential for both collaboration and communication.

With different languages factoring into all case studies, effective interpreters were essential for communication. When dealing with Inuktitut or Inuinnaqtun and English, it is not merely a matter of translating words, as literal translations almost never make sense when translated in either direction. The concepts and mind frames incorpo- rated into speech and word selection in each language are completely different, requiring a skilled interpreter to adequately communicate what is meant by statements in either language. In each case study, ample time was spent with interpreters to discuss the concepts of the research project and how they could be explored in the local culture, perceptions and language. Interpreters reviewed and commented on the interview/focus group questions prior to conducting any interviews, to ensure that the questions were appropriate, and that their interpretation of the questions was consistent with the research goals. The challenge of avoiding misinterpretation is everpresent, making ongoing communication and positive working relationship a necessary iterative element in community-environment research, if the knowledge shared is to be clearly understood and accurately portrayed.

In the Dorset-Pang-Igloolik study, the willingness of Inuit elders and hunters to participate in interviews and focus groups, and to take the researcher on experiential sea-ice trips, was essential in developing detailed and comprehensive results. Community members were more than informants in the conventional sense. Paid local researchers helped design the projects around the expertise of community members in an effort to accurately convey their knowledge in a manner that was locally acceptable. Through focus groups and sea-ice trips, several key individuals helped to refine and verify Inuktitut terminology, link terminology to photographs of ice conditions and review maps created during interviews. In each community, additional local experts were hired following the fieldwork, to further verify Inuktitut terminology and linkages (facilitated by local researchers). This helped to ensure a higher accuracy of results, and to give more meaningful presentations within the community context.

Notwithstanding the benefits of employing community members, there are challenges in achieving this engagement. These include difficulties identifying suitable candidates, community collaborators struggling to balance employment obligations with other priorities (i.e., land-use activities, family roles, other seasonal employment), and the economic subtext of employment relationships (Wolfe et al. 2007). The challenge of identifying suitable candidates was evident in the Ulukhaktok study, where the aim was to employ willing and available people with the necessary skills, and who had good rapport with community members. The researcher's two-week preliminary visit helped with gaining acceptance and appreciating characteristics of the community, its livelihoods, and institutions, but it was insufficient for identifying suitable local researchers. Using the hamlet office and posting job positions, the researcher 
encountered difficulties with uncertainty over impartiality. Eventually, following discussions with community representatives, the Elder's Council and Inuvialuit Cultural Resource Centre served as the decision-making bodies, and two candidates were selected.

Many community members and organizations in Arctic Canada believe that researchers should provide the maximum local economic benefit (local purchases and employment) possible through their research. These expectations have become a central factor in evaluating the quality of community-research relationships, and have caused conflict where there are differences between community and researcher perceptions of what is acceptable monetary compensation. Beyond payment for lodging, food, local transportation, etc., the economic relationships in community-environment research encountered in the case studies relate mainly to payment for: (a) work as a researcher, interpreter and/or guide (local collaborators), and (b) compensation for interviews and participation in meetings. In all case studies, work undertaken as employment was financially compensated. For example, work as an interpreter, translator or guide involved payment for services. Financial compensation rates for local collaborators were based on communication with the Northern research institute in the study regions. In communities that are being affected by rapid resource exploration and development, including Igloolik and Ulukhaktok, finding people willing to work for "research wages" as opposed to "mine and exploration wages" can be difficult, and suitable candidates tend to be those who wish to benefit from the experience and skill development as well as the income.

Guidelines to financial compensation for interviews and meetings are not as clear as they are for employment, and they vary among regions and communities, and over time. In the Ulukhaktok study, community representatives did not request financial compensation for interviewees or honoraria for participants in meetings, and because the research was being developed with the community, community representatives suggested that the research budget be used to hire two local high-school graduates to work as research assistants. In the Arctic Bay-Igloolik study, interview participants were compensated based on rates established by community organizations. In these communities, even though the research was developed in communication with the communities, it was expected that interviewees be paid in compensation for their time. In the Dorset-Pang-Igloolik study interviewees were also paid, as the convention was that people take time out of their schedules to participate, and payment offsets the money they are not making if they interrupt their employment, carving, hunting or fishing schedules. Since the increase in mining activity in the Igloolik region, some community members who previously participated in the research subsequently expressed dissatisfaction at the level of payment, and declined to be interviewed further. This emerging conflict points to the importance of continued re-assessment and negotiation of acceptable financial compensation for a participant's time in rapidly changing communities (ITK \& NRI 2007).

\section{Dissemination of results}

The dissemination of results in the partner community serves to inform community members of the status of the project, helps ensure the accuracy of results, lets a broader audience know of the results and provides an opportunity for community members to give feedback on the research. For research that aims to connect with policy and decision-making, results can be disseminated to other potential end-users or parties interested in the research (i.e., regional decision makers and government representatives). The experiences of the case studies show that effective dissemination requires a suitable time of year, the use of communication techniques that are well suited in a community context and an appropriate duration of time to allow people to provide feedback on the research.

In the Dorset-Pang-Igloolik study, dissemination and verification of preliminary results were conducted on each field research trip to the communities (four to each of Cape Dorset and Pangnirtung between April 2004 and May 2005; two to Igloolik between October 2004 and June 2005), using some of the communication methods described in the section on early and ongoing communication. In addition, to communicate finalized results and pursue further verification, reporting trips were arranged to Pangnirtung and Igloolik. The final Cape Dorset trip was cancelled because of weather delays and researcher illness, but all materials were mailed to the community, and organizations were contacted by telephone. Results were shared with the communities using bilingual summary reports, public meetings, a radio show, hardcopy maps, school presentations and copies of the original audio/video/transcript data that were stored in the settlement. Researchers worked closely with local researchers in each community to generate bilingual summary reports that were distributed to each individual who had participated in the project (via interviews or sea-ice trips), as well as local organizations who had supported the project with their interest and feedback. These provided a good overview of results that had been refined by community feedback in the previous fieldwork trips in each community; however, some community members preferred oral communication. Thus, public meetings were 
organized to complement written communications. Interestingly, these drew more interest from people who had not been involved in the project, and thus represented basic information sessions. Although the sessions atended by 10-20 people addressed those who were particularly interested (and who were not out on the land), and allowed detailed information exchange, to engage larger numbers of community members information sessions would ideally be timed outside the spring hunting periods, or to coincide with other public meetings being held at the same time.

Additionally, a radio show was conducted in Igloolik to highlight key findings (the radio station airtime was strictly limited in Pangnirtung because of local community event planning at the time). This again helped to reach a broad audience, noted by people who would mention to the researcher the next day that they were happy to hear the results on the radio. School presentations and the provision of hard-copy maps were other ways of giving information back to the community. These techniques, especially the maps, sparked discussions of results, their potential uses in the community and future directions for research. However, it is difficult to evaluate the lasting utility of these methods of reporting, as it is less evident how a presentation influences a student, or how young hunters use the maps, for example, in times following the departure of the researcher. From the general feedback received, the more personal, interactive and visual aspects of results dissemination were the most appreciated by community members, and thus should be emphasized as important elements of any communication or dissemination strategy, alongside the more academic reporting and outputs that are expected of researchers (e.g., thesis, journal publications, book chapters and summary reports).

Project results were disseminated in Ulukhaktok between mid-July and mid-September 2006, a year after the main data collection trip. The timing of this visit was established with community representatives to correspond with the start of the new school year in August, and the return of most families to the community from camping on the land. The researcher worked with the local researchers and interpreter to develop dissemination materials (bilingual summary reports), and shared the research findings in the community through household visits, and with presentations to the school and to community organizations (e.g., Hamlet Council and HTC), and to an elder's lunch and drum dance. The bilingual summary reports incorporated pictures and other visual elements with simple text, and were made available to community members at the hamlet office and during individual household visits. Initial attempts by the researcher and an interpreter to conduct household visits were not effective. Household visits to collect feedback were more effective when conducted by the local researchers and interpreter themselves, both because the communication was smoother and because people felt more comfortable sharing their thoughts on the research with people they knew.

An elder's lunch and drum dance was organized to show appreciation for the community's involvement in the research, and inform community members on the status of the research and the availability of dissemination materials. Summary booklets were distributed, the researcher was available to answer questions and a slide show was presented. School presentations were made to share research findings with the younger generation of community members. The staff at Helen Kalvak Elihakvik School in Ulukhaktok were exceptionally welcoming and supportive of the research, and they invited the researcher and research assistants to share project updates and project findings with students. School presentations facilitated further discussions on how results can be used in the community, community research needs and youth involvement in future research. Following these presentations, four students pursued their interest in the research topic and engaged in a discussion on "youth perspectives" on environmental change. These discussions developed into a presentation that was given by the students at the Coastal Zone Canada Youth Forum in August 2006, held in Tuktoyaktuk, NWT.

In the Arctic Bay-Igloolik study, dissemination trips of one and half weeks were made to each community in March and April 2005. Although this is a busy time of year for hunting in the communities, it was identified as a good time period to share results as people hunt close to the settlements at this time of year, and it is prior to the spring hunting season, when most community members travel further out on the land. In each case study, researchers together with ITK and local collaborators developed a variety of accessible dissemination media, including town-hall style presentations, follow-up interviews with people interviewed for the project, radio shows, leaflets and an information CD. Bilingual summary reports were designed by researchers and community collaborators to be free of jargon, to be concise and to emphasize the key findings using both text and pictures.

Feedback was encouraged throughout dissemination visits in all of the partner communities, and community members had the opportunity to share their thoughts on the research in English or Inuinnaqtun/Inuktitut. Community feedback was incorporated into the final project results through an additional review and verification stage of research findings and an element of local critique of the research process. For example, in the Dorset-Pang- 
Igloolik study, elders and hunters expressed their interest in having the documented sea-ice terminology, features and conditions more accessible in an educational format for use in the communities. This has been acted upon, in the development of follow-up research that is part of an International Polar Year project, the Inuit Sea Ice Use and Occupancy Project, to render previously documented materials more accessible and interactive in an online educational atlas framework, for use in the curriculum of Nunavut schools. In addition, communities expressed an interest in learning about what climatic changes are being experienced by other communities and in other Arctic regions, and about what adaptation strategies are being used to cope with these changes. Another International Polar Year project, Community Adaptation and Vulnerability in Arctic Regions (CAVIAR), is building upon existing community-environment research and community-research relationships to conduct vulnerability studies with communities across the circumpolar Arctic, to better understand how Arctic communities are affected by environmental changes, and to help inform adaptive strategies and policies. The communities involved in the case studies have remained actively involved in one or more of these projects, and it was the foundation of the earlier relationship-building, communication and results dissemination that enabled these collaborations to continue.

\section{Conclusions}

Community-environment research requires active collaboration with community members. Developing a research project with an Arctic community is a shared process that will evolve from mutual trust, and an understanding of the cultural context in which the research is being conducted. It is a negotiation between researchers and community members to identify and balance the needs, interests and expectations of both parties (ITK \& NRI 2007). The four considerations described in this paper for involving communities in communityenvironment research are intended to help facilitate these negotiations. Early and ongoing communication provides opportunities to identify interested community partners, link with existing research projects, develop communityresearcher relationships, and communicate research progress and findings in the community. Involving community members in research design and development through pre-research consultation visits allows for the mutual development of research foci, methodologies, research timing and duration, mediums and channels for communication, and community-researcher relationships. Providing employment as local researchers and interpreters is important for building community support for and participation in the research, facilitating communication between researchers and communities, and interpreting and verifying data. Disseminating results in the partner communities serves to inform community members of the status of the project, ensure the accuracy of results, share the results, and provides an opportunity for community members to give feedback on the research. Ongoing and effective communication is important in each of these considerations, and throughout the entire research process from initial planning to the start of the project, during fieldwork and reporting on the final project results. Strong communication between researchers and the partner community throughout the research process provides opportunities to develop, monitor, evaluate and improve the research as it progresses.

The nature of community-research relationships will differ among research projects, and will evolve based on the type of research and the particular characteristics of each community. There is no one "correct" set of methods for engaging Arctic communities in collaborative research; however, there are well-established protocols for undertaking research with communities in the Canadian Arctic. These protocols have been documented by Northern governments, Northern research institutes, Inuit organizations, and researchers in research licensing guides and reports. Together with these and other resources, the experiences described in this paper are offered as considerations for effectively engaging Arctic communities in collaborative community-environment research.

\section{Acknowledgements}

The authors thank the residents, hamlet councils, and hunters and trappers organizations/committees in Ulukhaktok, Arctic Bay, Igloolik, Cape Dorset, Pangnirtung and Iqaluit for their assistance and partnership. We would especially like to acknowledge the assistance of Emily Kudlak, Mel Pretty, Winnie Akhiatak, Gary Okheena, Adam and Melanie Kudlak, John McDonald, Leah Otak, Ooleepeeka Arnaqaq, Tirak Parr, Adam Scott and Marie Puddister, and the constructive suggestions of two anonymous reviewers.

The case study research was possible through financial support from: ArcticNet, IPY Canada, the Canada Research Chairs Programme, the Department of Indian and Northern Affairs Canada NSTP Program, Aurora Research Institute Fellowship and Assistantship Programs, Arthur D. Latornell Foundation, Social Sciences and Humanities Research Council of Canada, Natural Resources Canada Canadian Climate Impacts and Adaptations Program, Canadian Foundation for Innovation, University of Guelph Graduate Studies Research and Recruitment Scholarships, Ocean Management Research Network 
Integrated Management Node Student Seed Grant, Cryosphere System in Canada program, Northern Ecosystem Initiative, Society of Women Geographers Evelyn L. Pruitt National Fellowship for Dissertation Research, University of Toronto Fellowships, Association of Canadian Universities for Northern Studies Canadian Polar Commission Scholarship and Rhodes House Scholarship.

Research in Ulukhaktok, Arctic Bay and Igloolik was undertaken as part of the Global Environmental Change Group at the University of Guelph, and was conducted under NWT Scientific Research Licenses nos. 13832N and 14025R, and NRI License no. 0203204N-M, respectively. Research in Cape Dorset, Igloolik and Pangnirtung was undertaken through the Department of Geography at the University of Toronto, and was conducted under NRI Research License no. 0100504N-M.

\section{References}

ACUNS (Association of Canadian Universities for Northern Studies) 2003. Ethical principles for the conduct of research in the North. Ottawa: Association of Canadian Universities for Northern Studies.

Adger N., Arnell N. \& Tompkins E. 2005. Successful adaptation to climate change across scales. Global Environmental Change 15, 77-86.

ARCUS (Arctic Research Consortium of the United States) 2004. Guidelines for improved cooperation between Arctic researchers and Northern communities. Fairbanks: Arctic Research Consortium of the United States.

ARI (Aurora Research Institute) 2004. Doing research in the Northwest Territories: a guide for researchers. Inuvik, Northwest Territories: Aurora Research Institute.

Berkes F. 1999. Sacred ecology: traditional ecological knowledge and resource management. Philadelphia: Taylor $\&$ Francis.

Berkes F., Colding J. \& Folkes C. 2000. Rediscovery of traditional ecological knowledge as adaptive management. Ecological Applications 10, 1251-1262.

Berkes F. \& Jolly D. 2002. Adapting to climate change: social-ecological resilience in a Canadian western Arctic community. Conservation Ecology 5(2), article no. 18.

Berkes F., Mathias J., Kislalioglu M. \& Fast H. 2001. The Canadian Arctic and the Oceans Act: the development of participatory environmental research and management. Ocean $\theta$ Coastal Management 44, 451-469.

Bielawski E. 1984. Anthropological observations on science in the North: the role of the scientist in human development in the Northwest Territories. Arctic 37, 1-6.

Birket-Smith K. 1929. The Caribou Eskimos. Parts I and II. Report of the Fifth Thule Expedition 1921-24. Copenhagen: Gyldendalske Boghandel.

Boas F. 1888. The Central Eskimo. In J.W. Powell (ed.): Sixth annual report of the Bureau of American Ethnology to the Secretary of the Smithsonian Institution 1884-1885. Pp. 399-669. Washington D.C.: Government Printing Office.
Brice-Bennett C. (ed.) 1977. Our footprints are everywhere: Inuit land use and occupancy in Labrador. Nain, NL: Labrador Inuit Association.

Brody H. 1981. Maps and dreams: Indians and the British Columbia frontier. Vancouver: Douglas and McIntyre.

Brooks R., M'Lot M. \& McLachlan S. 2006. Pitfalls to avoid when linking traditional and scientific knowledge. In R. Riewe \& J. Oakes (eds.): Climate change: linking traditional and scientific knowledge. Pp. 13-20. Winnipeg: Aboriginal Issues Press, University of Manitoba.

Chambers R. 1994. The origins and practice of participatory rural appraisal. World Development 22, 953-969.

Chapin F.S. III, Hoel M., Carpenter S., Lubchenco J., Walker B., Callaghan T., Folke C., Levin S., Maler K., Nilsson C., Barrett S., Berkes F., Crepin A., Danell K., Rosswall T., Starrett D., Xepapadeas A. \& Zimov S. 2006. Building resilience and adaptation to manage Arctic change. Ambio 35, 198-202.

CIHR (Canadian Institute for Health Research) 2007. CIHR Guidelines for Health Research Involving Aboriginal Peoples. Ottawa: Canadian Institute for Health Research.

Cohen S. 1997. Scientist-stakeholder collaboration in integrated assessment of climate change: lessons from a case study of northwest Canada. Environmental Modeling and Assessment 2, 281-293.

Collings P., Wenzel G. \& Condon R. 1998. Modern food sharing networks and community integration in the central Canadian Arctic. Arctic 51, 301-314.

Condon R., Collings P. \& Wenzel G. 1995. The best part of life: subsistence hunting, ethnicity, and economic adaptation among young adult Inuit males. Arctic 48, 31-46.

Crate S. 2006. Investigating local definitions of sustainability in the Arctic: insights from post-Soviet Sakha villages. Arctic 59, 294-310.

CYFN (Council of Yukon First Nations) 2000. Traditional knowledge research guidelines: a guide for researchers in the Yukon. Whitehorse, YT: Council of Yukon First Nations.

Damas D. 1963. Igluligmiut kinship and local groupings-a structural approach. Ottawa, ON: National Museum of Canada.

Duerden F. 2004. Translating climate change impacts at the community level. Arctic 57, 204-212.

Duerden F. \& Kuhn R. 1998. Scale, context, and application of traditional knowledge of the Canadian North. Polar Record 34, 31-38.

Eamer C. 2006. Research licensing in Northern Canada: an overview. Whitehorse, YT: Daley Networks.

Ellis S.C. 2005. Meaningful consideration? A review of traditional knowledge in environmental decision making. Arctic 58, 66-77.

Fienup-Riordan A. 1983. The Nelson Island Eskimo: social structure and ritual distribution. Anchorage: Alaska Pacific University Press.

Feit H. 1973. Ethno-ecology of the Waswanipi Cree-or how hunters can manage their resources. In B. Cox (ed.): 
Cultural ecology readings on the Canadian Indians and Eskimos. Pp. 115-125. Toronto: McClelland and Stewart.

Ford J., Macdonald J., Smit B. \& Wandel J. 2006. Vulnerability to climate change in Igloolik, Nunavut: what we can learn from the past and present. Polar Record 42, 127-138.

Ford J., Pearce T., Smit B., Wandel J., Allurut M., Shappa K., Ittusujurat H. \& Qrunnut K. 2007. Reducing vulnerability to climate change in the Arctic: the case of Nunavut, Canada. Arctic 60, 150-166.

Ford J., Smit B. \& Wandel J. 2006. Vulnerability to climate change in the Arctic: a case study from Arctic Bay, Canada. Global Environmental Change 16, 145-160.

Ford J., Smit B., Wandel J., Allurut M., Shappa K., Ittusujurat H. \& Qrunnut K. 2008. Climate change in the Arctic: current and future vulnerability in two Inuit communities in Canada. The Geographical Journal 174, $45-62$.

Fox S. 2002. These are things that are really happening: Inuit perspectives on the evidence and impacts of climate change in Nunavut. In I. Krupnik \& D. Jolly (eds.): The Earth is faster now: indigenous observations of climate change. Pp. 12-53. Fairbanks: Arctic Research Consortium of the United States.

Freeman M. (ed.) 1976. Inuit land use and occupancy project. Vols. 1-3. Ottawa: Department of Indian and Northern Affairs.

Freeman M. 1992. The nature and utility of traditional ecological knowledge. Northern Perspectives 20, 9-12.

Furgal C. \& Prowse, T. 2008. Northern Canada. In D. Lemmen et al. (eds.): From impacts to adaptation: Canada in a changing climate 2007. Pp. 57-118. Ottawa: Government of Canada.

Furgal C. \& Seguin J. 2006. Climate change, health, and vulnerability in Canadian Northern aboriginal communities. Environmental Health Perspectives 114, 1964-1970.

Gamble R. 1984. A preliminary study of the Native harvest of wildlife in Keewatin Region, Northwest Territories. Technical Report No. 1282. Winnipeg: Fisheries and Oceans Canada.

Gearheard S., Matumeak W., Angutikjuaq I., Maslanik J., Huntington H.P., Leavitt J., Kagak D.M., Tigullaraq G. \& Barry R.G. 2006. "It's not that simple": a collaborative comparison of sea ice environments, their uses, observed changes, and adaptations in Barrow, Alaska, USA, and Clyde River, Nunavut, Canada. Ambio 35, 203-211.

Gearheard S. \& Shirley J. 2007. Challenges in community-research relationships: learning from natural science in Nunavut. Arctic 60, 62-74.

GeoNorth 2000. Climate change impacts and adaptation strategies for Canada's Northern Territories: final workshop report. Yellowknife: GeoNorth (prepared for Natural Resource Canada and Environment Canada).

Gibbs M. 2001. Toward a strategy for undertaking cross-cultural collaborative research. Society and Natural Resources 14, 673-687.
GN (Government of Nunavut) 2003. Nunavut climate change strategy. Iqaluit, NU: Government of Nunavut.

GNT (Government of the Northwest Territories) 2005. Policy: traditional knowledge. Yellowknife: Government of the Northwest Territories.

GNT (Government of the Northwest Territories) 2008. NWT climate change impacts and adaptation report. Yellowknife: Northwest Territories Environment and Natural Resources. GNTBS (Government of the Northwest Territories Bureau of Statistics) 2007. Summary of NWT community statistics. Yellowknife: Government of the Northwest Territories Bureau of Statistics.

GTZ (Gesellschaft für Technische Zusammenarbeit) 1988. ZOPP: an introduction to the method. Eschborn, Germany: Gesellschaft für Technische Zusammenarbeit.

GY (Government of Yukon) 2006. Government of Yukon climate change strategy. Whitehorse: Government of Yukon.

Handley J., Fentie D.Y. \& Okalik P. 2007. A Northern vision: a stronger north and a better Canada. Whitehorse: Premier's Office Yukon Government, Premier's Office Government of the Northwest Territories, Premier's Office Government of Nunavut.

Huntington H. 1998. Observations on the utility of the semi-directed interview for documenting traditional ecological knowledge. Arctic 51, 237-242.

Huntington H., Trainor S., Natcher D., Huntington O., DeWilde L. \& Chapin S.I. 2006. The significance of context in community-based research: understanding discussions about wildfire in Huslia, Alaska. Ecology and Society 11, $1-40$.

Huntington H.P. 2000. Using traditional ecological knowledge in science: methods and applications. Ecological Applications 10, 1270-1274.

IJS (Inuvialuit Joint Secretariat) 2003. Inuvialuit harvesters survey. Data and methods report 1988-1997. Inuvik, NT: Inuvialuit Joint Secretariat.

Instanes A., Anisimov O., Brigham L., Goering D., Khrustalev L.V., Ladanyi B. \& Larsen J.O. 2005. Infrastructure: buildings, support systems, and industrial facilities. In C. Symon et al. (eds.): Arctic climate impact assessment. Pp. 908-944. Cambridge: Cambridge University Press.

ITK \& NRI (Inuit Tapiriit Kanatami \& Nunavut Research Institute) 2007. Negotiating research relationships with Inuit communities: a guide for researchers. Iqaluit and Ottawa: Inuit Tapiriit Kanatami and Nunavut Research Institute.

Jenness D. 1922. The life of the Copper Eskimos. Report of the Canadian Arctic Expedition 1913-18. Vol. 12. Ottawa: F.A. Acland.

Keene A. 1985. Nutrition and economy: models for the study of prehistoric diet. In R. Gilbert \& J. Mielke (eds.): The analysis of prehistoric diet. Pp. 155-190. New York: Academic Press.

Kemp W. 1971. The flow of energy in a hunting society. Scientific American 224(3), 104-115.

Kruse J.A., White R.G., Epstein H.E., Archie B., Berman M., Braund S.R., Chapin F.S. III, Charlie J., Daniel C.J., Eamer 
J., Flanders N., Griffith B., Haley S., Huskey L., Joseph B., Klein D.R., Kofinas G.P., Martin S.M., Murphy S.M., Nebesky W., Nicolson C., Russell D.E., Tetlichi J., Tussing A., Walker M.D. \& Young O.R. 2004. Modeling sustainability of Arctic communities: an interdisciplinary collaboration of researchers and local knowledge holders. Ecosystems 7, 815-828.

Laidler G.J., Dialla A. \& Joamie E. 2008. Human geographies of sea ice: freeze/thaw processes around Pangnirtung, Nunavut. Polar Record 44, 335-361.

Laidler G. \& Elee P. 2008. Human geographies of sea ice: freeze/thaw processes around Cape Dorset, Nunavut, Canada. Polar Record 44, 51-76.

Laidler G.J. \& Ikummaq T. 2008. Human geographies of sea ice: freeze/thaw processes around Igloolik, Nunavut, Canada. Polar Record 44, 127-153.

McCarthy J., Canziani O.F., Leary N.A., Dokken D.J. \& White K.S. (eds.) 2001. Climate change 2001: impacts, adaptation and vulnerability. Contribution of Working Group II to the third assessment report of the Intergovernmental Panel on Climate Change. Cambridge: Cambridge University Press.

McCarthy J. \& Martello M. 2005. Climate change in the context of multiple stressors and resilience. In C. Symon et al. (eds.): Arctic climate impact assessment. Pp. 945-988. Cambridge: Cambridge University Press.

NCP (Northern Contaminants Program) 2007. Northern contaminants program guidelines for responsible research. Accessed on the internet at www.ainc-inac. gc.ca/nth/ct/ncp/pubs/omg/omg-eng.asp on 1 January 2009.

Nelson R. 1969. Hunters of the northern ice. Chicago: Aldine.

Nelson R. 1973. Hunters of the northern forest: designs for survival among the Alaskan Kutchin. Chicago: University of Chicago Press.

Nichols T., Berkes F., Jolly D., Snow N. \& the Community of Sachs Harbour 2004. Climate change and sea ice: local observations from the Canadian western Arctic. Arctic 57, 68-79.

Nickels S., Furgal C., Buell M. \& Moquin H. 2006. Unikkaaqatigiit - putting the human face on climate change: perspectives from Inuit in Canada. Ottawa: Inuit Tapiriit Kanatami, Nasivvik Centre for Inuit Health and Changing Environments at Universite Laval; Ajunnginiq Centre, National Aboriginal Health Organization.

Nickels S., Furgal C., Castleden J., Moss-Davies P., Buell M., Armstrong B., Dillon D. \& Fonger R. 2002. Putting the human face on climate change through community workshops: Inuit knowledge, partnership, and research. In I. Krupnik \& D. Jolly (eds.): The Earth is faster now: indigenous observations of Arctic environmental change. Pp. 301-333. Fairbanks: Arctic Research Consortium of the United States.

Noongwook G., Savoonga T.N.V., Gambell T.N., Huntington H. \& George J. 2007. Traditional knowledge of the bowhead whale (Balaena mysticetus) around St. Lawrence Island, Alaska. Arctic 60, 47-54.
NTI (Nunavut Tunngavik Incorporated) 2008. Licensing process. Accessed on the internet at www.nri.nu.ca/ lic_process.html on 1 January 2009.

Nunavut Land Claim Agreement: an agreement between the Inuit of the Nunavut Settlement Area and Her Majesty the Queen in Right of Canada. 1993. Accessed on the internet at www.nucj.ca/library/bar_ads_mat/Nunavut_Land_Claims_ Agreement.pdf on 1 January 2009.

Nuttall M., Berkes F., Forbes B., Kofinas G., Vlassova T. \& Wenzel G. 2005. Hunting, herding, fishing, and gathering: indigenous peoples and renewable resource use in the Arctic. In C. Symon et al. (eds.): Arctic climate impact assessment. Pp. 649-690. Cambridge: Cambridge University Press.

Ohmagari K. \& Berkes F. 1997. Transmission of indigenous knowledge and bush skills among the western James Bay Cree women of subarctic Canada. Human Ecology 25, 197-222.

Pearce T. 2006. Vulnerability and adaptation to environmental change in Ulukhaktok. MA thesis, University of Guelph.

Rasmussen K. 1932. Intellectual culture of the Copper Eskimos. Report of the Fifth Thule Expedition 1921-24. Vol. 9. Copenhagen: Gyldendalske Boghandel.

Riewe R. (ed.) 1992. Nunavut atlas. Edmonton: Canadian Circumpolar Institute.

Sallenave J. 1994. Giving traditional ecological knowledge its rightful place in environmental impact assessment. Northern Perspectives 22, 16-19.

Shirley J. 2005. C-CIARN North: Nunavut community research needs survey. Iqaluit, NU: Nunavut Research Institute.

Smit B. \& Wandel J. 2006. Adaptation, adaptive capacity and vulnerability. Global Environmental Change 16, 282-292.

Smith T. \& Wright H. 1989. Economic status and role of hunters in a modern Inuit Village. Polar Record 25, 93-98.

Statistics Canada 2006. 2006 community profiles. Accessed on the internet at wwwl2.statcan.ca/english/census06/ data/profiles/community/Index.cfm?Lang=E on 1 January 2009.

Stefansson V. 1913. My life with the Eskimos. New York: Collier Books.

Stevenson M.G. 1996. Indigenous knowledge in environmental assessment. Arctic 49, 278-291.

Symon C., Arris L. \& Heal B. (eds.) 2005. Arctic climate impact assessment. Cambridge: Cambridge University Press.

Tester F. 2006. IGLUTAQ: the implications of homelessness for Inuit-a case study of housing and homelessness in Kinngait, Nunavut Territory. Vancouver: University of British Columbia.

Tremblay M., Furgal C., Lafortune V., Larrivee C., Savard J., Barrett M., Annanack T., Enish N., Tookalook P. \& Etidloie B. 2006. Communities and ice: linking traditional and scientific knowledge. In R. Riewe \& J. Oakes (eds.): Climate change: linking traditional and scientific knowledge. Pp. 123-138. Winnipeg: Aboriginal Issues Press, University of Manitoba.

Turner B., Kasperson R., Matson P., McCarthy J., Corell R., Christensen L., Eckley N., Kasperson J., Luers A., 
Martello M., Polsky C., Pulsipher A. \& Schiller A. 2003. A framework for vulnerability analysis in sustainability science. Proceedings of the National Academy of Sciences 100, 8074-8079.

Tyler N., Turi J., Sundest M., Bull S.K., Sara M., Reinert E., Oskal N., Nellemann C., McCarthy J., Mathiesen S., Martello M., Magga O., Hovelsrud G., Hanssen-Bauer I., Eira N., Eira I. \& Corell R. 2007. Saami reindeer pastoralism under climate change: applying a generalized framework for vulnerability studies to a sub-Arctic social-ecological system. Global Environmental Change 17, 191-206.

Usher P. 2000. Traditional ecological knowledge in environmental assessment and management. Arctic 53, 183-193.

Watt-Cloutier S., Fenge T. \& Crowley P. 2005. Responding to global climate change: the perspectives of the Inuit Circumpolar Conference on the Arctic climate impact assessment. Ottawa: Inuit Circumpolar Conference.

Wenzel G. 1981. Clyde Inuit adaptation and ecology: the organization of subsistence. Ottawa: National Museum of Man.

Wenzel G.W. 1999. Traditional ecological knowledge and Inuit: reflections on TEK research and ethics. Arctic 52, 132-124.
Wesche S. \& Armitage D. 2006. Adapting to environmental change in a northern delta system. In R. Riewe $\delta$ J. Oakes (eds.): Climate change: linking traditional and scientific knowledge. Pp. 105-120. Winnipeg: Aboriginal Issues Press, University of Manitoba.

Wiita A. 2006. The culture of community-based research and a borderless North. Paper presented at the 4th Northern Research Forum Open Meeting, 5-8 October, Oulu, Finland and Lulea, Sweden.

Wolfe B., Armitage D., Wesche S., Brock B., Sokal M., Clogg-Wright K., Mongeon C., Adam M., Hall R. \& Edwards T. 2007. From isotopes to TK interviews: towards interdisciplinary research in Fort Resolution and the Slave River Delta, Northwest Territories. Arctic 60, 75-87.

Woo M., Modeste P., Martz L., Blondin J., Kochtubajda B., Tutcho D., Gyakum J., Takazo A., Spence C., Tutcho J., Di Cenzo P., Kenny G., Stone J., Neyelle I., Baptiste G., Modeste M., Kenny B. \& Modeste W. 2007. Science meets traditional knowledge: water and climate in the Sahtu (Great Bear Lake) region, Northwest Territories, Canada. Arctic 60, 37-46. 